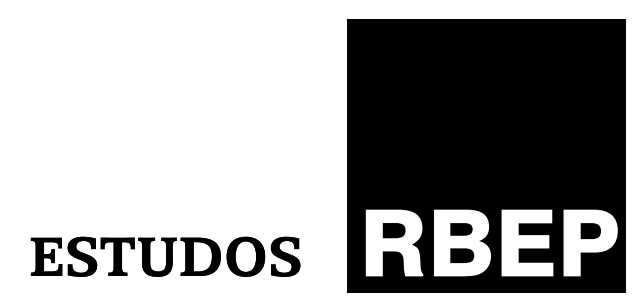

\title{
Revistas de escolas católicas do Rio de Janeiro nos anos 1920-1950: religião e educação
}

Miriam Waidenfeld Chaves

\section{Resumo}

Este trabalho procura expor os primeiros resultados de uma pesquisa histórica que tem como foco privilegiado de análise as revistas escolares de três escolas católicas do Rio de Janeiro nos anos 1920-1950. Tem-se como objetivo mostrar que os valores, comportamentos e atitudes ali produzidos/transmitidos/assimilados se constituíram de forma variada a partir de três ideias nucleares: a) valorização do passado por meio da constante referência aos seus fundadores, patronos, ex-professores e ex-alunos; b) ligação inequívoca entre religião e ciência; c) crença de que aquelas escolas estariam formando parcela significativa da elite brasileira que mais tarde iria ocupar os cargos de destaque da política, da cultura e da ciência nacionais.

Palavras-chave: colégios católicos; revistas escolares; Rio de Janeiro; anos 1920-1950. 


\section{Abstract \\ Catholic schools journals in Rio de Janeiro in 1920/1950: religion and education}

This paper aims to present the first results of a historical research mainly focused on the analysis of school journals of three Catholic schools in Rio de Janeiro during the years 1920-1950. The intention is to show that values, behaviors and attitudes produced/transmitted/ assimilated by those schools were formed in a varied way from three core ideas: a) the recovery of the past through constant reference to its founders, patrons, former teachers and former students, b) unequivocal link between religion and science, c) belief that those schools would form a significant portion of the Brazilian elite that would later hold major positions in politics, culture and national science.

Keywords: catholic schools; school journals; Rio de Janeiro; 19201950 years.

As pesquisas no interior do campo da história da educação têm nos surpreendido na medida em que os estudos culturais continuam apontando novas formas de compreensão acerca da escola. Ao nos sugerir novos temas, fontes e objetos, fornecem um olhar cada vez mais acurado sobre essa instituição moderna que, apesar de possuir pouco mais de um século, fixou-se como um dos espaços mais competentes de socialização.

Estas possibilidades tornam-se, ainda, inesgotáveis, caso se tenha como foco três escolas católicas - Colégio de São Bento, Colégio Santo Inácio e Colégio São José - do Rio de Janeiro, nos anos de 1920 a 1950. Primeiro porque os estudos sobre as práticas culturais escolares basicamente se referem à escola pública; muito pouco foi pesquisado a respeito da cultura escolar das escolas católicas, uma importante fração do nosso sistema de ensino nacional, principalmente em relação à formação das elites. Segundo porque os impressos pesquisados, apesar de terem se transformado em um rico manancial de fonte/objeto, ainda têm como foco principal a formação de professores. Ou seja, os historiadores da educação que se debruçam sobre esse tema, em sua maioria, têm feito uma análise sobre as revistas pedagógicas que tinham como objetivo instruir, informar e formar o professor de acordo com as novas filosofias da educação da época ou, ainda, uma investigação sobre os impressos que se estruturaram com alguma intenção associativa e organizativa do grupo, enquanto categoria profissional (Villela, 2002; Catani, Bastos, 2002; Schueler, 2005). 
Terceiro porque o período privilegiado - 1920-1950 - tem a educação como o centro das discussões políticas do País, tornando-se inviável pensar um projeto nacional sem um projeto educacional; questão que a partir daquele momento em diante se limita a um conflito de interesses entre tecnocratas, donos de escolas, professores e estudantes. Cada qual agindo, apenas, de acordo com seus interesses particulares e sem uma percepção mais ampla quanto ao papel que a educação deveria desempenhar em nossa sociedade (Schwartzman, Bomeny, Costa, 2000, p. 281-282).

As revistas A Vitória Colegial, publicada pelos alunos do Colégio Santo Inácio na década de 1950, A Alvorada, escrita nos anos de 1920 a 1930, pertencente ao Colégio de São Bento, e a Echos, editada pelo Colégio São José durante a década de 1920, são as fontes privilegiadas deste texto.

Cabe ressaltar que os impressos são escritos e têm como seu público-leitor o aluno do curso secundário, nível de ensino ainda pouco conhecido por nós, historiadores da educação.

Eles foram divididos em três partes. Enquanto na primeira faz-se uma breve consideração acerca da relevância dos estudos culturais, mais especificamente da importância dos impressos pedagógicos para este tipo de abordagem, na segunda é mostrado como o pensamento católico por meio de seu projeto educacional transforma a Igreja em uma das instituições de maior destaque da sociedade brasileira durante os anos de 1920 a 1950, possibilitando, inclusive, que se constitua em uma das principais instâncias formadoras da nossa elite nacional. Na última parte, resguardada a especificidade de cada revista em função do período de publicação e da ordem religiosa a que pertence cada escola, é apresentada uma análise sobre algumas ideias nucleares que, de modo recorrente, aparecem em forma de artigo nas três publicações.

\section{As revistas escolares dos colégios católicos: uma territorialidade cultural ad intra}

Este trabalho torna possível uma análise sobre as instituições escolares católicas por meio de sua produção material: as revistas escolares, objetos materiais onde se incrustam vestígios de uma história que, sob nossa ótica, é compreendida não apenas mediante as grandes teorias que unificam e homogeneízam a realidade social, mas também a partir da especificidade e diversidade existente no interior de cada impresso de cada escola.

Inspirado em algumas ideias de Jaques Revel (1998, p. 10), procurase, com o auxílio dos registros dos agentes envolvidos com as revistas, uma outra maneira de construção do social; mais exatamente, aquela que tenta dar às experiências vividas pelos autores dos artigos - alunos, professores, diretores e ex-alunos - um destaque que antes era desconsiderado em função da importância atribuída às estruturas e aos processos sociais anônimos e inconscientes.

Consequentemente, o papel das escolas católicas no cenário educacional brasileiro no período investigado não seria apenas entendido 
a partir de suas relações com a doutrina católica ou com o aparelho de Estado, mas, inclusive, por meio de suas revistas. Pressupor-se-ia uma análise sobre suas características de impressão, estratégias da escrita e intenção de seus produtores que definiriam não apenas as formas de sua escrita e impressão, mas também os modos de leitura que seus leitores poderiam seguir (Chartier, 1990, p. 121).

Os impressos, por se produzirem muito próximos do acontecimento (Nóvoa et al., 2002, p. 13), estariam, ainda, permitindo uma construção que teria como base as próprias experiências vividas pelos agentes envolvidos no processo de sua elaboração; enquanto escritos jornalísticos, encontram-se numa posição de reação aos fatos ou a ideias e normas legais, tornando a imprensa uma das melhores fontes para se compreender as incongruências entre a teoria e a prática.

Neste caso, este trabalho baseia-se em uma perspectiva ad intra (Nóvoa, 1995, p. 16) que pensa as revistas enquanto uma territorialidade cultural que, ao expressar o jogo dos agentes sociais com elas envolvidas, se situa entre a ação desses mesmos indivíduos e as imposições a que se encontram sujeitos por força do espaço social e cultural em que são editadas. Ao mesmo tempo que as revistas são compreendidas enquanto expressão das vivências e experiências dos autores dos artigos no interior das escolas católicas em que se encontram, também são consideradas como uma produção cultural que se materializa em certas instituições e em determinados momentos históricos, portanto, estariam submetidas a certas injunções que se engendrariam às suas próprias condições de produção.

Cabe também ressaltar que os agentes que escrevem para as revistas não são aqui entendidos como meros indivíduos isolados no interior da escola, mas, ao contrário, como alguém que compõe grupos diferenciados com diferentes propósitos; pressupondo experiências e escritas também diversificadas.

Assim, os artigos publicados expressariam um tipo de construção do social, que se realizaria na intercessão entre a experiência individual e a do grupo, e possibilitariam uma interpretação que leva em conta uma percepção bastante precisa da vida social e da relação entre as normas e os comportamentos já predeterminados por cada grupo em questão (Cerutti, 1998, p. 185).

Portanto, esta perspectiva ad intra estaria proporcionando um melhor entendimento sobre as formas de produção/recepção do ensinado/ aprendido que pressuporia o resultado de todo um processo social de aprendizagem. Este seria, então, compreendido como fruto de imbricações entre o que se impõe ensinar e o que se aceita e se nega aprender, e não apenas como um resultado final dos objetivos da escola.

\section{A Igreja Católica: os fins da educação}

De acordo com Mainwaring (2004), a fé, um fenômeno suprarracional, é o pressuposto básico da Igreja Católica. Entretanto, os estudos 
sociológicos sobre as relações da Igreja com a política ou mesmo com a cultura nos obrigam a pensá-la enquanto uma instituição que, como qualquer outra, objetiva sua preservação, com base na defesa de seus interesses particulares.

Nessa perspectiva, um olhar apurado sobre as ligações entre a Igreja, o Estado e a educação brasileira não pode deixar de detectar as lutas empreendidas pela primeira no sentido de propagar sua mensagem religiosa para um universo social cada vez mais abrangente.

Se o Brasil na Constituição de 1824 proclamou-se oficialmente católico, a Igreja, por sua vez, mantinha-se extremamente dependente do Estado Imperial e muito pouco ligada à Roma. Na República, se o Estado laico posiciona a Igreja a partir de um lugar mais equidistante do poder, aquela se liga diretamente à Roma e, ainda, se desenvolve de forma mais articulada em direção tanto ao aparelho de Estado quanto à sociedade (Mainwaring, 2004, p. 42).

Durante os anos de 1920 a 1950, a Igreja no Brasil atravessa várias fases. Nos anos de 1920 a 1930, aproxima-se em demasia do Estado devido às ligações entre Getúlio Vargas e Dom Sebastião Leme, líder da hierarquia católica e arcebispo de Olinda e depois do Rio de Janeiro, e ainda promove uma forte política de fabricação de uma elite que teria como função revitalizar a sua presença dentro das esferas política e social. Já nos anos de 1940 a 1950, a competição com as outras religiões e o declínio do monopólio religioso católico reestruturam as relações da Igreja com o Estado e a colocam frente à necessidade de desenvolver uma missão pastoral mais sistemática mediante a modernização de suas práticas e de um amplo projeto de formação de líderes pastorais (Mainwaring, 2004, p. 50).

Portanto, se as escolas selecionadas para esta análise são centenárias, suas histórias encontram-se pontuadas por esta atmosfera. Constituem-se, enquanto um locus privilegiado de fermentação e disseminação de certos valores, por meio da construção de um ideal pedagógico que estivesse em sintonia com a visão de mundo e de homem do cristianismo católico.

Esse ideal sustenta-se na crença de que o mundo ocidental moderno se encontra em uma crise de consciência ou intelectual (Cury, 1984, p. 29) na medida em que o laicismo ao invadir as sociedades, principalmente, a partir do século 19, impõe um estilo de vida que rompe com o sistema hierárquico das coisas, separando o homem de seu Criador.

Esse esquecimento de Deus implicaria uma reconstrução social do mundo com base em uma determinada visão de homem, de mundo, de sociedade e de Deus e suas mútuas relações. A tradição, a escolástica e o magistério seriam o sustentáculo desses princípios: o primeiro garantiria a preservação de uma herança católica que se deseja, perpetuando continuamente; o segundo fundamentaria filosoficamente o pensamento católico, dando-lhe o instrumental intelectual necessário para enfrentar os desafios propostos pelos novos tempos; e o último manteria uma "interpretação verdadeira" do cristianismo católico, sobretudo por intermédio das Encíclicas Papais (Cury, 1984, p. 41). 
Suas escolas, nesse caso, ao se erguerem a partir de tais premissas, organizam suas práticas e saberes mediante um tipo de pedagogia que procura atrelar o conhecimento a esses fins.

O ensino das matérias, por não poder ser entendido em separado da educação moral, só teria sentido a partir do que os educadores católicos denominam de educação integral, um tipo de ação pedagógica que implica uma teologia intelectual, cuja sustentação moral seria a mola propulsora de todos os demais aspectos do próprio ensino (Cury, 1984, p. 56).

A Igreja, o Estado e a família seriam as instâncias educacionais por excelência, cabendo a escola desempenhar um papel complementar que por meio de sua estrutura pedagógica e administrativa garantiria a continuidade do processo socializador já iniciado anteriormente. Deveria, ainda, encontrar-se em concordância com os valores proferidos por aquelas três instituições que, hierarquicamente ligadas pela ordem sobrenatural das coisas, formariam o verdadeiro cristão, desenvolvendo todos os aspectos de sua vida - sensível, espiritual, intelectual, moral, individual, doméstica e social (Foulquié, 1957, p. 228).

A Encíclica consagrada à educação dos jovens cristãos, editada em 1929, por Pio XI, ao proclamar a necessidade de a Igreja e o Estado se encontrarem unidos pela educação, procurará cumprir com essas determinações. Transforma, portanto, seus colégios em verdadeiros espaços de difusão dessas ideias que, nesse caso, se materializarão segundo as especificidades de cada congregação religiosa.

A presença dos jesuítas no Brasil data de 1567, ano em que criam o Colégio dos Jesuítas, tendo o padre Manoel da Nóbrega como seu primeiro reitor. São expulsos do Brasil em 1759, retornam em 1814, mas apenas em 1900, no Flamengo, é que se funda uma pequena escola primária, onde se ensinava música e se preparava para a primeira comunhão. Em julho de 1903, os padres se mudam para Botafogo, um outro bairro da zona sul, onde começa a funcionar o Externato Santo Inácio, hoje, Colégio Santo Inácio.

A chegada dos beneditinos ao Rio de Janeiro confunde-se com a história da cidade. Eles desenvolvem um trabalho de catequese e em 1858 fundam o Colégio de São Bento em uma região central onde a própria cidade teve sua origem. Primeiramente, constitui-se como um externato, funcionando nas dependências do mosteiro. É gratuito até 1915, quando a partir desta data dois tipos de estabelecimentos são criados: a velha escola que passa a receber contribuições e uma nova que é fundada para oferecer serviços gratuitos. Inicia um regime de internato, que é mantido até 1922, e em 1928 o colégio passa a admitir alunos em tempo integral.

Os maristas fixam-se no Rio de Janeiro em 1735, inaugurando o Seminário Diocesano de São José, próprio para a carreira eclesiástica. Em 1881, o curso preparatório para o seminário transfere-se para o Rio Cumprido, tradicional bairro da zona norte, e é equiparado ao ginásio nacional. Em 1902, o tradicional educandário passa a obedecer à orientação pedagógica dos Irmãos Maristas, e tem início sua trajetória enquanto internato e externato. 


\section{As revistas escolares: competentes espaços de socialização}

As publicações escolhidas, com certeza, não deixariam de expressar as formas de pensar descritas acima, principalmente durante as décadas de 1920 a 1950, período em que o movimento laicista se expande favorecendo sobremaneira as escolas estatais. Estas se transformam em fortes concorrentes dos colégios pertencentes às diversas ordens religiosas que, sem alternativas, depositam naqueles a missão de propagar o seu ideal educacional. A iniciativa de diretores, professores e alunos para que as escolas mantivessem uma ou várias revistas seria apenas um sinal do quanto se mostrava necessária a comunicação entre a comunidade escolar, que assim poderia reforçar seus ideais e evitar o enfraquecimento dessa comunicação por mensagens adversas.

Além desses aspectos, as revistas teriam como objetivo contribuir para o desenvolvimento da vida associativa da comunidade escolar. Colaborariam com o ensino na medida em que estimulassem a escrita dos alunos, incentivados a desenvolver suas opiniões, argumentação e ideias por meio dos artigos que liam/escreviam. E, ainda, funcionariam como porta-vozes de seus mentores, numa tentativa de deixar registrado aquilo que se desejava que fosse lembrado no futuro.

Antes de iniciar a análise das revistas, cabe frisar que a particularidade de cada impresso não foi esquecida. Se as prioridades educacionais variaram de escola para escola e de década para década, o que se pretende neste momento é mostrar como os artigos selecionados induzem certos comportamentos a fim de que seus leitores reproduzam aquilo que seus autores desejavam que fosse apreendido e internalizado. Ou ainda, acredita-se que os artigos publicados pelos diferentes agentes - alunos, reitores, professores e diretores - possam ser interpretados como a própria mensagem que as escolas quisessem ver fixada pelo seu público escolar.

\subsection{As condições de produção das revistas}

Para a Análise do Discurso (Maingueneau, 1989), a intenção subjacente da enunciação expressa a tensão entre a linguagem e o social. Sugere que se estruture a partir das mediações "entre" o texto em seu estado bruto e os agentes ou grupos que o produzem. Conforme palavras da própria autora:

É preciso ainda pensar que o próprio espaço de enunciação, longe de ser um simples suporte contingente, um "quadro" exterior ao discurso, supõe a presença de um grupo específico sociologicamente caracterizável, o qual não é um agrupamento fortuito de "portavozes".

Não basta dizer que entre as informações brutas e os jornais existe o mundo da imprensa. De fato, não se dispõe, inicialmente, dos escritores ou dos cidadãos; a seguir, das instituições mediadoras e, por fim, 
dos enunciados em circulação, mas tudo emerge ao mesmo tempo.

(Maingueneau, 1989, p. 54-55, grifos da autora).

Esta afirmação pressupõe que os modos de existência dos impressos pesquisados encontram-se na imbricação entre os artigos, as revistas e aqueles que as produzem/consomem, que, neste caso específico, subordinam-se a certas instituições que procuravam salvaguardar seu espaço no cenário educacional brasileiro.

Devido aos avanços teóricos no âmbito da história cultural, uma análise de texto também não pode mais ser pensada sem o seu suporte. À perspectiva acima descrita deve-se somar àquela proposta por Chartier (1990, p. 121), quando afirma que uma análise sociocultural do texto pressupõe não perder de vista a ideia de que aquele não existe fora do objeto que o comunica, e isto, sem sombra de dúvida, faz parte da significação. Considera-se, então, a materialidade do próprio texto, suas condições de impressão e editoração a fim de que se possa compreendê-lo em sua totalidade, ou seja, a partir das condições históricas de sua produção.

Compete ainda ressaltar que, se as revistas são compreendidas como um objeto cultural que possui vários sentidos, esta análise não se esgota em si mesma. E este trabalho, ao levar em conta essa afirmação, apenas indica algumas conclusões possíveis referentes ao suporte, explicitando frequência, periodicidade e estratégias editoriais (tamanho, capa, etc.), e ao texto, por meio da seleção e interpretação de um conjunto de artigos que imediatamente nos chamaram a atenção por se acreditar que expressariam certos valores de uma educação típica dos colégios católicos.

Não se trata de uma análise em separado de cada revista, com descrição exaustiva das linhas gerais e programáticas ou, ainda, com exposição de tabelas classificatórias das seções e artigos mais frequentes. Trata-se apenas de um estudo com resultados parciais na medida em que deles emergem alguns princípios-chave que, acreditamos, sustentariam a ação pedagógica dos colégios católicos selecionados. Ou seja, apesar de a análise resguardar certas características específicas de cada impresso relativas a sua materialidade, observa-se que os sentidos do discurso dos artigos se repetem, apontando para um modelo de pensamento com, pelo menos, três ideias comuns: a exaltação da fé, da tradição e da distinção, elementos que embasariam a educação de elite dos estabelecimentos de ensino investigados.

Portanto, esta exposição tem como objetivo enfatizar a reprodução de um padrão que ecoa para além das páginas das revistas, indicando-nos certas formas de escolarização que aqui são caracterizadas como próprias dos colégios católicos.

\subsubsection{Frequência e periodicidade}

Os impressos, muitas vezes, atravessam décadas, dando uma demonstração clara de força e vigor. 
A revista A Vitória Colegial começa a ser editada na década de 1940 - uma vez que o primeiro exemplar encontrado na escola refere-se a 1950 como o Ano X ${ }^{1}$ - e é publicada mensalmente, em uma média de seis, sete ou oito revistas por ano. Os anos de 1951, 1955, 1956 e 1958 editam seu primeiro número em abril e o último em novembro, sem interrupção, perfazendo um total de oito exemplares no ano. Enquanto em 1953, 1957 e 1959 existem sete edições anuais, de modo geral, sem o mês de julho, os anos de 1950, 1952 e 1954 conseguem produzir apenas seis números em cada ano.

Em relação à revista A Alvorada, Dom Lourenço, reitor do Colégio de São Bento, em sua página na internet, faz questão de enumerar todas as publicações da escola. Afirma que existiram os periódicos: A Alvorada, fundado em 1918 e mantido até os anos de 1960; Avante, órgão da academia literária, dos anos 1950 e 1960; Jornal do São Bento, pertencente ao grêmio; $O$ Leão, entre outros.

Foram encontrados na biblioteca do colégio os números relativos aos anos de 1922 a 1928 e, ainda, os de 1932, 1933, 1935 e 1936 da revista A Alvorada, perfazendo um total de 54 publicações. As edições são mensais ou bimestrais. Enquanto os números da década de 1920 são, na sua maioria, bimestrais, variando de seis a quatro exemplares anuais, os relativos aos da década de 1930 não são regulares, passando a existir seis edições em 1932 e 1933, cinco em 1935 e quatro em 1936.

Ao contrário dos demais periódicos, o Echos é editado anualmente. ${ }^{2}$ Iniciando sua publicação em 1904, os 11 números disponíveis para análise referem-se aos anos de 1920 a 1930.

\subsubsection{O suporte das revistas: as estratégias editoriais}

Os periódicos têm sempre o mesmo formato e utilizam uma medida padrão, $21 \mathrm{~cm} \times 15 \mathrm{~cm}$, de fácil manuseio. Impressos em gráficas da cidade e recheados de fotografias, mostram uma grande preocupação com a sua produção que só pode ser descrita como sendo de muito cuidado, esmero e sofisticação.

Cada exemplar de A Vitória Colegial possui em torno de 35 páginas, de A Alvorada aproximadamente 20 e de Echos uma média de 100 páginas anuais.

O tamanho dos textos é diversificado. Há uma preferência pelos mais longos - com no mínimo meia página, podendo chegar a três, quatro ou cinco -, indicando a necessidade de um domínio da escrita e da leitura por parte dos alunos.

As capas e as contracapas demonstram ser o resultado de muito trabalho e elaboração, constituindo-se em importante estratégia de editoração. A revista periódica Echos, como se autointitula, tem a capa mais trabalhada.

Até 1923, as capas são rebuscadas e cheias de detalhes. São inspiradas em pinturas antigas, com desenhos de flores, folhas de parreiras e colunas de mármore que servem para emoldurar o desenho que,

\footnotetext{
1 Achavam-se na biblioteca da escola 67 exemplares referentes à década de 1950. Os números de setembro de 1950, março de 1951 e novembro de 1952 não foram encontrados.

2 Os exemplares foram enviados por correio, pelo Centro de Estudos Maristas, em Belo Horizonte.
} 
ainda, contém sobre si o nome do periódico e do colégio escrito em letras góticas. Já as capas dos anos seguintes são mais simples. Enquanto no alto da página se mantêm as flores, as folhas e os nomes da revista e da escola em letras desenhadas, abaixo passa a existir uma foto imponente da escola ou dos alunos à frente dela.

A sobriedade é o princípio que caracteriza as próximas páginas introdutórias. Na primeira, em uma "respeitosa homenagem" ou affectueux hommage, encontra-se o desenho de um pergaminho com o nome da alta hierarquia católica da época. Na seguinte, tem-se a foto de Dom Joaquim Arcoverde e na última delas a figura de Dom Sebastião Leme, autoridades católicas.

As edições da revista A Alvorada podem ser analisadas a partir de dois momentos. O primeiro refere-se à década de 1920, em que não há uma capa, mas uma primeira página, onde no alto dela existe um desenho de uma alvorada, contendo um sol, um riacho, uma montanha, poucas árvores e uma construção ao alto. Logo abaixo, encontram-se escritos o nome da revista, um importante lembrete de que a publicação possui a "Aprovação da autoridade eclesiástica" e, logo a seguir, o ano, o mês e o número da edição. Na outra metade da página, um texto que pode seguir até a próxima página.

A outra fase inicia-se nos anos de 1930. A capa contém, ao alto, com letras retas e em destaque, o nome da revista, a substituição do "Com a aprovação da autoridade da escola" por "Órgão Oficial do Ginásio de São Bento" e, logo após, uma fotografia imponente do prédio da escola. Surge uma contracapa, antes inexistente, com o sumário. Entretanto, os exemplares de 1935 e 1936 têm sua capa modificada.

Ao invés da simplicidade de antes, é estampado um desenho da escola sobre nuvens e, logo abaixo, ao que tudo indica, um outro da Igreja e do mosteiro da escola. Este todo se encontra envolto por uma coroa de louro, onde no alto se lê em latim Veritati et Virtuti. Abaixo, um pergaminho servindo de base; à esquerda, há um tinteiro e uma pena; e, à direita, um globo terrestre. Ao pé da página, ainda, há desenhado o símbolo da escola sobre a inscrição "Órgão Oficial do Ginásio de São Bento", Rio de Janeiro, Brasil.

Estes expedientes não só ligam os impressos a sua escola e a ordem religiosa a que pertencem como, também, as engrandecem, indicando que aqueles se encontram envoltos em uma aura de tradição que se conecta às origens do catolicismo. A utilização de determinados símbolos - o latim, a coroa de louro e as folhas de parreira - demonstra um apreço por certos elementos do passado que povoam o imaginário religioso, remetendo o leitor a uma ambiência pouco conectada com a realidade concreta. Exemplo esse que pode ser constatado por meio das capas da revista A Alvorada, de 1935 e 1936, onde o prédio da escola encontra-se literalmente entre as nuvens, pairando no céu; ou seja, no alto, sobre as vidas dos indivíduos.

Além disso, ainda há certos sinais que mostram as capas e as contracapas enquanto síntese daquilo que se quer preservar: a ordem, a 
obediência e a aceitação da hierarquia. O nome e as fotos dos dirigentes católicos impressos na Echos, a "autorização" mais explícita ou não "Órgão Oficial do Colégio de São Bento " - e a presença de padres na direção de um "periódico dos alunos" indicam que as revistas só são editadas porque há uma prévia permissão dos dirigentes dos colégios. ${ }^{3}$

As capas da revista A Vitória Colegial, apesar de resguardarem certos elementos religiosos, tais como a presença, em close, de Cristo, Nossa Senhora e Santo Inácio, em sua maioria são compostas por fotografias dos próprios alunos. Ainda que raro, em outras já aparecem o nosso índio e também as crianças negras, num claro reconhecimento de que o mundo também é composto por outros povos.

Consequentemente, as capas da revista A Vitória Colegial se apresentam da seguinte forma: contêm apenas uma foto e, abaixo, o nome da revista. Na contracapa, novamente, encontram-se ao alto o nome do impresso e abaixo o dizer "Periódico dos alunos do Colégio Santo Inácio", o endereço da escola, o diretor responsável e o vice-diretor - padres -, o ano, o mês, o número da edição, o sumário e, curiosamente, uma explicação sobre o significado da capa, aspecto que merece ser ressaltado.

Estas explicações junto com as fotografias mostram que a revista é utilizada como autorreferência dos alunos na medida em que são seus principais personagens: quando nela se encontram, há, na contracapa, um texto explicativo, inclusive informando o nome dos alunos que nela aparecem, numa clara intenção de individualizá-los, deixando-os orgulhosos.

"Cadetes da Aeronáutica? Apenas nossos alunos Gilberto Pereira e João Paulo Mariz num avião-escola do Campo dos Afonsos" (vestidos como cadetes ao lado de um avião), "Fábio Penna Lacombe, na mandíbula de um tubarão não teme o perigo!!!" (dentro de um tubarão de pano) e "Marcílio de Lemos e Pedro Pinheiro Guimarães, alunos do Colégio Santo Inácio. Coroinhas do altar, ajudando o sacerdote na Santa Missa..." são apenas alguns exemplos.

As explicações e as fotografias indicam que os alunos estão em algum momento alegres e descontraídos, fruto de uma cena do cotidiano. Demonstram, ainda, que o impresso deseja repassar a ideia de um clima escolar jovial cuja figura do aluno é fundamental. Principalmente nos anos 1950, momento em que a cultura jovem desponta no cenário internacional, obrigando o colégio a se encontrar em sintonia com essas mudanças.

Os nomes das revistas também revelam uma intenção bastante explícita. Echos, ainda escrito em latim Echo, quer dizer "lembrança, recordação e vestígio"; "repercussão"; ou "pessoa ou entidade que repete ou propaga o que é dito por outrem". Por meio desses sinônimos, pode-se inferir que a revista gostaria de deixar rastros. Objetivava marcar seu leitor com suas ideias, que deveriam espalhar-se de forma cada vez mais crescente.

A Alvorada significa "crepúsculo, a claridade que precede o romper do sol", mas, principalmente, "princípio, começo e início", enfim, algo que vem antes. Nesse caso, pode-se afirmar que a revista desejaria ser compreendida como um veículo de comunicação que deve servir de base,

\footnotetext{
${ }^{3}$ No próximo item, esta questão será mais explorada.
} 
cimento sólido a partir do qual se constrói outras ideias que viriam apenas posteriormente.

O nome A Vitória Colegial sintetiza um dos lemas da revista: seus autores e/ou leitores estariam fadados ao "sucesso", "triunfo", ou, ainda, ao "êxito brilhante em qualquer campo de ação".

3.1.3 Os produtores das revistas (diretores, professores e alunos): uma relação assimétrica

Detectar os responsáveis pelas revistas implica chamar a atenção para os mecanismos de apagamento e de explicitação daqueles que se encontram envolvidos com essa operação. Pressupõe colocar o foco nos indivíduos ou grupos de indivíduos que as editam com o objetivo de captar as intencionalidades de cada um desses grupos para com as revistas.

A Echos afirma tratar-se de uma "Revista periódica", não fazendo questão de identificar seus produtores. Inclusive, os artigos praticamente não são assinados. Apenas o primeiro texto, intitulado "Caros Alunos", sugerindo que a revista é feita para alunos, encontra-se identificado: Irmão Sapôr ou Irmão Mauro Cristóvão - reitores. Essa característica demonstra que o impresso se achava sob o controle da direção da escola e que os alunos possuíam uma participação restrita. A presença deles é percebida por discursos de formatura, transcritos nas revistas, e por ex-alunos que, já adultos, voltam à escola para servirem de exemplo aos que ainda estudam.

A revista A Alvorada também não se preocupa em identificar seus produtores, assim como os de alguns de seus artigos. Entretanto, faz questão de deixar claro que se trata de uma publicação autorizada, já que em momentos diferentes inscreve na capa "Com a aprovação da autoridade eclesiástica" e, posteriormente, " Órgão Oficial do Colégio de São Bento".

O primeiro artigo da revista também merece um comentário. Ao final, muitas vezes, tem inscrito "A Redação"; o nome do autor por extenso (José Piragibe, Clovis Monteiro e Abdias Silva); e o primeiro nome (Plácido) ou, apenas, as iniciais (D. M. O. ou simplesmente M.), numa demonstração de que eram reconhecidos enquanto professores. Os alunos participam por meio da coluna "Nossos Trabalhos", onde assinam seus textos.

Entretanto, nada mais esclarecedor do que o artigo "Origem da $A$ Alvorada", de João Rezende, ex-aluno, publicado na edição de março de 1922:

Aluno ainda, conversando um dia com Antônio de Matos Lopes, foi entre nós, sugerida a ideia de fundar-se, neste ginásio, um grêmio literário e uma revista para os alunos...

E assim se fundou A Alvorada.

Pedimos artigos a vários professores e fomos gentilmente atendidos pelo Dr. Mário Barreto - o maior filólogo brasileiro, na opinião de Rui Barbosa; pelo Dr. José Piragibe, mestre que sabe falar ao coração dos discípulos; D. Plácido Roth... 
E foi com juvenil orgulho de vencedores que levamos o primeiro número ao Revmo. D. Abade... Dois ou três dias depois D. Meinrado trazia-nos a grata notícia de que o ginásio pagaria grande parte das despesas, mas condicionalmente: A Alvorada deveria ser dirigida por um dos professores do colégio e sofrer a fiscalização de D. Reitor. Foi escolhido para guiá-la a contento de todos nós o Dr. Piragibe, o mesmo que duvidara da sua viabilidade.

Por iniciativa do Revmo. D. Plácido, A Alvorada muda de feitio e sai em formato de revista; já não é um jornalzinho de alunos e sim para os alunos, destes só serão publicados os artigos que de fato merecerem (p. 3-4).

Conclui-se que o desejo dos alunos em ter um jornal só se tornou possível porque a direção do colégio atrela sua existência à responsabilidade de um professor. Deixa, assim, de ser um "jornalzinho de alunos" para se transformar, mediante uma intervenção "consentida", em uma revista "para os alunos", onde eles só publicarão "os artigos que de fato merecerem". Portanto, a direção limita sua participação e a transfere para as mãos dos professores que os transformam em uma revista.

A Vitória Colegial, já na contracapa, explicita que se trata de um "Periódico dos alunos do Colégio Santo Inácio". Entretanto, logo abaixo, encontra-se o nome do diretor responsável, sempre padre. Apesar de se tratar de uma revista de alunos que os posiciona como um grupo importante, eles ainda não são inteiramente responsáveis pela sua produção.

Diante das estratégias editoriais acima descritas, percebe-se que os grupos de dirigentes, professores e alunos possuem participação variada na elaboração das revistas. Posicionam-se de acordo com as relações de força estabelecidas junto à produção e ao consumo do que se escreve e lê nas revistas, tornando seu envolvimento com os impressos algo bastante assimétrico.

Na Echos, o grupo "visível" é o dos dirigentes, pouco se sabendo sobre professores e alunos. Haveria uma relação direta, sem intermediários - os professores -, entre a direção, escrevendo os artigos, e os alunos, lendo aquilo que a direção gostaria que soubessem. Ou seja, a direção concebe a revista e os alunos, uma massa de leitores indeterminados, receberiam-na para consumi-la por meio de sua leitura.

Na revista A Alvorada, ao contrário, os três grupos estão presentes e os professores passam a desempenhar um importante papel delegado pela direção. São eles, com algumas personalizações - José Piragibe -, que escrevem os artigos e se responsabilizam pela sua qualidade, a qual é submetida à direção que tem poder de veto. Os alunos, por sua vez, têm um lugar garantido nas páginas da revista, além de outras funções, como solicitar artigos, ir à gráfica, etc.

Enquanto grupo, desempenham um papel ainda mais relevante na revista A Vitória Colegial. Esta, além de se intitular uma revista de alunos, tem seus artigos publicados majoritariamente por esse grupo; entretanto, a direção, indiretamente, supervisiona o periódico. 
Outro aspecto relevante da revista é que existe um forte processo de individuação do grupo de alunos. Alguns deles escrevem regularmente para a revista, tornando possível a elaboração de seu perfil. Um exemplo refere-se à participação de Arnaldo Jabor, aluno do clássico, que publica suas histórias em capítulos durante o ano de 1959.

\subsection{Os sentidos do discurso}

Apesar da diversidade, é possível apreender um solo comum que caracterizaria as três revistas. A valorização do passado, a ligação da ciência aos princípios religiosos e a crença de que as escolas formavam uma elite cultural e social bem sucedida seriam os elementos que fermentariam esse terreno, permitindo, inclusive, uma compreensão sobre a educação católica a partir dos artigos selecionados para análise.

\subsubsection{Culto ao passado}

A revista Echos por meio da presença da alta hierarquia católica em suas primeiras páginas demonstra a importância da tradição para referendar tanto o passado quanto o presente da instituição.

No exemplar de 1920, os artigos "Beatificação do Padre Champagnat", fundador do Colégio na França em 1817, e "Festa do patrocínio de São José" confirmam este culto à origem da escola que deve ser permanentemente lembrada, principalmente porque aqueles mediante suas vidas deveriam inspirar seus leitores.

Por meio da revista também se percebe que a associação dos ex-alunos tinha como objetivo manter vivo no presente o seu passado. A edição de 1929, no artigo "Aos nossos antigos alunos", confirma este pressuposto. Reforça a ideia de que a qualidade da escola no presente é legitimada pelo que ela representou no passado ao transformar seus ex-alunos em homens de bem que honram o que lhes foi ensinado na escola:

\footnotetext{
Nossos caros antigos alunos conservam suas convicções religiosas, praticam seus deveres de cristãos, honram seus mestres, são chefes de família exemplares, tornando-se alguns verdadeiros apóstolos do bem. Muitos conhecemos que ocupam lugares de destaque e cargos de responsabilidade na sociedade (p. 25)
}

Esta mesma prática pode ser identificada na revista A Alvorada, em seu exemplar de 1932, no artigo "O primeiro aluno deste ginásio", escrito pelo estudante Eliomar de Sá Cavalcanti, da quinta série:

Quem terá sido o primeiro aluno deste ginásio? Certamente alguns logo responderão: um médico, outros um advogado, um terceiro um oficial do exército ou da marinha. Pensarão erradamente...

Nos registros do Colégio de São Bento notaremos à folha 11, na lista dos matriculados em primeiro lugar o nome de Francisco José Villaça. E o que foi mais tarde esse aluno? Monge beneditino. 
A Providência Divina quis abençoar esse instituto com um favor excepcional, dando ao primeiro aluno do ginásio a graça da vocação de beneditino. (p. 1).

Esta reportagem insinua que o primeiro aluno seja visto como um símbolo, como alguém que personificaria tudo aquilo que os demais alunos no futuro deveriam ser. Que fossem médicos, advogados ou oficiais da marinha, mas, prioritariamente, que o espírito beneditino se encontrasse entranhado em suas vidas.

O artigo "São Bento - adolescente", de março de 1923, demonstra que a melhor estratégia para se abordar o passado seria por meio do culto ao santo que nomeia a escola. A vida dele na adolescência serve de exemplo aos jovens alunos do colégio.

O passado na revista A Vitória Colegial também é alvo de destaque pela presença de Santo Inácio, Anchieta e outros santos nas páginas dos seus exemplares. Os artigos mostram que esses homens santos encontram-se ligados ao colégio devido a sua origem e que por esta razão os alunos deveriam se sentir orgulhosos, já que teriam tão ilustres antepassados compondo a história de seu colégio. Enquanto nos artigos "Santo Inácio. Homem ideal", de agosto de 1956, e "São José Pignatelli. O novo santo Jesuíta", de agosto de 1952, são ressaltadas as suas qualidades humanas e religiosas, no artigo "Anchieta, na fundação do Rio de Janeiro", de junho de 1956, narra-se a importância desse religioso na fixação da cidade no século 16.

Estes exemplos indicam que as revistas, ao reafirmarem sua crença no passado dos colégios, passam a ideia de que seu trunfo encontra-se em sua história que, nesse caso, garantiria a "boa educação" de seus alunos. Sugerem, ainda, que a autoridade advinda dessa posição privilegiada permite que tanto os autores quanto os leitores das revistas aceitem esse pressuposto, inclusive, divulgando-o.

Entretanto, este passado para o Colégio Santo Inácio encontra-se em movimento, possibilitando que os seus pares estejam em constante sintonia com o presente. O artigo "Jesuítas na atualidade", de setembro de 1954, indica que este colégio, apesar de ancorar o seu projeto educacional nas premissas de sua própria origem, procura estar atento às transformações sociais.

\subsubsection{Ligação da ciência à fé religiosa}

Os periódicos são enfáticos em mostrar a estreita vinculação entre a ciência e os princípios religiosos. Estes, ao contrário do que se poderia supor, não seriam obstáculos ao desenvolvimento daquela, na medida em que as coisas do mundo, inclusive a ciência, estariam hierarquicamente submetidas aos desígnios de Deus. À missa, portanto, deveria anteceder às aulas a fim de que aquela, por meio da mão invisível do Divino Espírito Santo, guiasse tanto docentes quanto discentes no sentido de não se distanciarem dos princípios da fé: 
Louvável costume nos colégios católicos o de, no começo do ano letivo, celebrar-se uma missa em honra do Divino Espírito Santo, para atrair sobre docentes e discentes as luzes do Alto, as bênçãos divinas.

O Colégio Diocesano São José, ufanando-se de pertencer ao número dos estabelecimentos de ensino onde não se divorcia a religião da ciência, conserva amorosamente a tradição de implorar o Espírito da Luz antes de iniciar o árduo labutar contra a ignorância. (Echos, 1920, p. 12).

Alcides Borges, autor do artigo "A química nos tempos pré-históricos", publicado na revista A Alvorada em abril de 1932, mostra que a universidade, enquanto espaço de produção científica, poderia, inclusive, desvirtuar o jovem ex-aluno do Colégio de São Bento. Chama atenção para os valores religiosos aprendidos no colégio que não deveriam ser esquecidos na universidade:

A maioria jactanciosa como costuma ser os homens de meia ciência julga inútil a discussão no terreno das altas cogitações...

É preciso que os nossos moços pisem na Universidade com a convicção de que a Ciência que vão estudar não obscurece nunca a Verdade. É preciso que conheçam que o tesouro espiritual que levam é superior ao cabotinismo espetaculoso da maioria dos pseudos sábios. (p. 6, grifo do autor).

A Igreja seria, então, a instituição que se posicionaria acima de todas as demais. O artigo "A Igreja, a instituição mais bela e sagrada de todos os tempos", publicado na edição de setembro/outubro de 1932, comprova essa afirmação:

É a história que no-lo afirma. Tem a Igreja sido há quase dois mil anos o alvo de todos os remoques, de todas as contradições...

É um mistério perene e profundo a Igreja! Percorremos devagar, com ponderada reflexão as páginas da História; que de crises sociais, desorientações convulsas, choques violentos, incertezas e amarguras não encontramos! E, no entanto, a Igreja descerrando as suas asas brancas como um arcanjo de bondade, paz e misericórdia, em todas as idades, nós a vemos chamando os homens para lhes abrandar a índole ferina, para lhes iluminar o cérebro obscurecido e os aquecer ao encontro de um coração onde só há amor desinteressado e inesgotável.

Quantas escolas, museus, hospitais, creches, leprosários, universidades, conferências de caridade, casas de regeneração e previdência, obras de salvação da infância, não foram criação sua e não vivem do seu influxo? (p. 140).

Esta superioridade da fé religiosa pode ser comprovada por meio do artigo "Fé e ciência", da revista Echos de 1921:

Repugna absolutamente que a fé seja incompatível com a ciência, sendo irmãs gêmeas, procedentes do mesmo princípio, da mesma causa, do mesmo pai, Deus, que exige dos homens a fé para lhe serem agradáveis. E é o senhor de todas as ciências. 
A fé, ensina o angélico doutor S. Tomaz, não destrói a ciência, senão a aperfeiçoa, completa e nobilita e onde não pode chegar esta por si, solevada nas azas daquela, descortina novos e vastos horizontes, que debalde procuram sondar os incrédulos.

Antes, afirmamos que a ciência não pode separar-se da fé, sem perigo de naufragar fatalmente nas mais ridículas aberrações humanas. (p. 6).

Na revista A Vitória Colegial dos alunos do Colégio Santo Inácio também é possível perceber essa relação. E, sendo a universidade a instituição que poderia abalar os princípios cristãos dos alunos oriundos dos colégios católicos, estes, por meio dos jesuítas, fundam a sua universidade católica, garantindo que a relação entre fé e ciência não saia dos trilhos. Conclui-se que a revista, por meio do artigo publicado em outubro de 1950, "Pontifícia Universidade Católica do Rio de Janeiro", escrito pelo próprio secretário geral da universidade, chega a uma solução "razoável" no que se refere a esta problemática:

Formar sábios, investigadores intelectuais, habilitá-los ao trabalho que faz progredir a ciência, laurear diretores ou ensinantes dos demais: função doutoral, função científica, formar profissionais das chamadas carreiras livres, homens possuidores de conhecimentos científicos indispensáveis a uma aplicação prática específica...

\begin{abstract}
De cada ramo do saber, o investigador católico trabalha com alegria de quem está certo de que sondando os mistérios da natureza, repensa os pensamentos do Criador, na frase profunda de Kepler, e com a confiança profunda de que todo passo adiante no descobrimento da verdade é um progresso no conhecimento de Deus e de seus desígnios na história da humanidade. (p. 11).
\end{abstract}

Neste sentido, a "boa educação" perseguida pelos colégios católicos não contrapõe a relação entre fé e ciência. Pelo contrário, o ensino rigoroso das matérias pressuporia um sólido viés ético que garantiria uma ação pedagógica de base religiosa, sobretudo em tempos cada vez mais laicos. De outro lado, confirmando o artigo anteriormente citado, "Jesuítas na atualidade", A Vitória Colegial publica inúmeros artigos sobre ciência, demonstrando que sua ligação com a fé não dificulta o seu compromisso com o que há de mais moderno em termos de conhecimento científico. Alguns títulos falam por si: "Telescópio", "O Brasil na era da aviação a jato" e "A verdade sobre a corrida do espaço".

\title{
3.2.3 Formação das elites cariocas
}

É fato que a educação das escolas católicas encontra-se atravessada pelos princípios da fé cristã. Entretanto, a formação intelectual de seu público não pode deixar de ser preenchida pelo que há de melhor na "alta cultura" na medida em que aquele se compõe de crianças e adolescentes que mais tarde irão ocupar os postos de destaque da sociedade. O ensino, desse modo, compunha-se de uma formação geral que enfatizava, além da religião, a necessidade de aprendizagem 
da Língua Portuguesa, da Literatura, da Filosofia e, como se mostrou acima, da própria ciência.

Os artigos longos e complexos são recheados de conceitos e formulações teóricas, pressupondo que o aluno, leitor número um das revistas, domine o assunto abordado nos textos.

Na revista A Alvorada ainda é comum a presença de artigos traduzidos, mostrando certo requinte no que se refere às escolhas do que deve ser publicado para ser, posteriormente, lido. "Traduções e tradutores", de agosto de 1932, comprova que esta questão era algo importante para a revista.

Os artigos "A reforma literária de Klopstock", "A origem do teatro", "A poesia brasileira antes do Romantismo" e "Paginas filosóficas", publicados na revista A Alvorada, e "Beethoven", "O teatro", "Machado de Assis" e o "O gênio de Leonardo da Vinci", escritos para A Vitória Colegial, demonstram o quanto certo conhecimento dito "desinteressado" compunha o universo educacional do autor/leitor dos impressos das escolas católicas investigadas.

O requinte desta postura atinge o seu limite com o artigo em francês "Le Rev. Frère Diogène, Superieur dês Frères Maristes", de duas páginas, publicado na revista Echos de 1920.

Entretanto, o aluno autor/leitor destas revistas para estar em condições de produzi-las e consumi-las deveria, segundo o professor José Piragibe do Colégio de São Bento, seguir a risca as recomendações publicadas, em junho/julho de 1922, no sugestivo artigo "O Trabalho intelectual", de cinco páginas. Nele, enumeram-se seis regras que "o trabalhador intelectual" deveria obedecer para alcançar o seu intento:

Não pensarás, estou certo, que se mencionam aqui todas as regras a que deve obedecer o trabalhador intelectual. Mando-te apenas as fundamentais, donde decorrem ou que inspiram muitas outras que o operário intelectual descobrirá sem intervenção de conselheiros..

Daí a primeira regra, ler. (p. 56).

Conclui-se, sem nenhum embargo, que as escolas investigadas formam "intelectuais", ou melhor, uma elite cultural que mais tarde irá comandar a nação.

As três revistas ainda fazem questão de manter o seu quadro de honra, no qual se encontram inscritos o nome, muitas vezes, a média e a foto dos melhores alunos do ano letivo e, também, daqueles que com sucesso cumpriram sua trajetória escolar entrando para a universidade ou Escola Naval, destino "natural" desse grupo de alunos.

"Panthéon", "Quadro de Honra" e "Guarda de Honra" são respectivamente as colunas das revistas Echos, A Alvorada e A Vitória Colegial. Responsáveis por dar visibilidade aos melhores alunos, estes espaços ao mesmo tempo que enaltecem os estudantes que cumpriram com os seus deveres, diferenciando-os dos demais e fazendo-os se sentirem orgulhosos de si, também geram naqueles que não conseguiram tal feito um 
sentimento, cujo fim é estimulá-los a estarem lá em uma próxima vez. Ou seja, esta individuação deslancharia um processo competitivo entre eles que procurariam esforçar-se para continuar ou, dependendo da situação, ter o seu nome inscrito pela primeira vez na coluna, tendo este espaço cumprido com sua função.

Essa postura procura incutir a ideia de que os alunos dos colégios católicos compõem um grupo especial, diferentes dos demais grupos de estudantes, que, mais tarde, comporá uma pequena confraria caracterizada, justamente, pelo fato de possuir determinadas qualidades tanto intelectuais quanto morais que lhe são próprias; o que já de antemão lhe garante uma certa distinção. O artigo, de agosto de 1922, da revista $A$ Alvorada com um título sugestivo, "Ilustres visitantes", sugere o tipo de nobreza que a referida educação escolar católica reserva para os seus:

Entre os numerosos personagens que, no decorrer do ano do nosso Centenário, arribam às plagas da terra da Santa Cruz, contam-se não só luminares do mundo científico, artístico e literário, mas principalmente chefes da Igreja católica, sábios que antepõem a todos os conhecimentos humanos a sabedoria que vem de Deus, a ciência dos Santos, a filosofia do Crucificado. (p. 85).

Portanto, os colégios católicos reservam para seus alunos a possibilidade de construírem uma vida de exceção, que se destina apenas para poucos escolhidos.

\section{Considerações finais}

Durante o período investigado, a Igreja teve que montar determinadas estratégias para competir com outras religiões que cada vez mais intensamente aportaram a nossa sociedade, e a reafirmação de seu compromisso com a educação escolar tornou-se uma excelente alternativa para que se mantivesse na disputa pela hegemonia religiosa.

Portanto, essa instituição cristã ao ter como objetivo criar uma liderança laica que reafirme seu poder junto a nossa sociedade, agora mais diversificada e heterogênea, transforma seus colégios em verdadeiros espaços de fermentação dessa nova geração de católicos. Ao formarem médicos, engenheiros, advogados, professores e arquitetos, enfim, a totalidade das profissões modernas, exigência da acelerada divisão social do trabalho, os colégios católicos têm garantido que os altos postos da sociedade sejam administrados por aqueles que foram socializados de acordo com seus princípios, garantindo, assim, o seu poder de influência tanto na sociedade quanto no aparelho do Estado.

Nesse sentido, enquanto produtos dessa época, as revistas analisadas expressam essa atmosfera social e cultural. Esforçam-se para que de suas páginas emanem certos valores, comportamentos e atitudes que precisariam ser assimilados por seus autores e seus leitores. Procuravam, então, garantir que as mensagens apregoadas pelos colégios fossem 
reinterpretadas em seus artigos que, inclusive, poderiam ser considerados verdadeiros porta-vozes dos colégios.

Ao divulgarem a pedagogia católica, as revistas ainda estariam reforçando as lições efetuadas em sala de aula e, consequentemente, reafirmando um tipo de ensino que se enquadraria aos padrões católicos da educação escolar. E este fato adicionado a uma série de outras estratégias contribuiria para que a própria Igreja continuasse conservando seu poder de influência na sociedade.

Cabe acrescentar que as três revistas compõem um todo ao mesmo tempo diversificado e homogêneo. A despeito das diferenças, expostas no texto, encontram-se atravessadas por certas características que, de acordo com nossa hipótese, reafirmariam uma escolarização típica dos colégios católicos.

Por último, é justo que se atente para o fato de que as revistas, apesar de envolverem a totalidade da comunidade escolar - reitores, diretores, professores e alunos - em sua produção, organizam-se de forma assimétrica, imprimindo à sua concepção os cânones da Igreja: aceitação da hierarquia. Ou seja, enquanto revistas dos colégios - mesmo A Vitória Colegial, considerada uma revista de alunos -, a decisão sobre o que era publicado encontrava-se nas mãos da direção dos colégios, grupo hierarquicamente superior também na produção das revistas. Confirmase, então, a importância estratégica dessas publicações para a Igreja: disseminar suas mensagens com o intuito de formar uma nova geração de católicos.

\section{Referências bibliográficas}

ALVORADA (A). Rio de Janeiro: [sem editora], 1922-1928, 1932, 1933, 1935, 1936.

CATANI, Denice Bárbara; BASTOS, Maria Helena Câmara (Orgs.). Educação em revista: a imprensa periódica e a história da educação. São Paulo: Escrituras, 2002.

CERUTTI, Simona. Processo e experiência: indivíduos, grupos e identidades em Turim no século XVII. In: REVEL, Jacques (Org.). Jogos de escalas: a experiência da micro-análise. Rio de Janeiro: FGV, 1998.

CHARTIER, Roger. A história cultural: entre práticas e representações. Lisboa: Difel, 1990.

ECHOS. Rio de Janeiro: [sem editora], 1920-1930.

CURY, Carlos R. Jamil. Ideologia e educação brasileira: católicos e liberais. São Paulo: Cortez, 1984. 
FOULQUIÉ, Paul. A Igreja e a educação. Rio de Janeiro: Agir, 1957.

MAINGUENEAU, Dominique. Novas tendências em análise do discurso. Campinas: Pontes, 1989.

MAINWARING, Scott. Igreja católica e política no Brasil. São Paulo: Brasiliense, 2004.

NÓVOA, Antonio. Por uma análise das instituições escolares. In: NÓVOA, Antonio (Org.). As organizações escolares em análise. Lisboa: Dom Quixote, 1995.

NÓVOA, Antonio et al. A imprensa de educação e ensino: concepção e organização do repertório português. In: CATANI, Denice Bárbara; BASTOS, Maria Helena (Org.). A imprensa pedagógica e a história da educação. São Paulo: Escrituras, 2002.

REVEL Jacquel. Micro-análise e construção do social. In: REVEL, Jacques (Org.). Jogos de escalas: a experiência da micro-análise. Rio de Janeiro: FGV, 1998.

SCHUELER, Alessandra Frota. Representações da docência na imprensa pedagógica na corte imperial. Educação e Pesquisa, São Paulo, v. 31, n. 3, p. 379-390, 2005.

SCHWARTZMAN, Simon; BOMENY, Helena Maria B.; COSTA, Vanda Maria Ribeiro. Tempos de Capanema. Rio de Janeiro: FGV, 2000.

VILLELA, Heloisa. Imprensa pedagógica e constituição da profissão docente no século XIX: alguns embates. In: GONDRA, José (Org.). Dos arquivos à escrita da história: a educação brasileira entre o império e a república. Bragança Paulista, EDUSF, 2002.

VITÓRIA COLEGIAL (A). Rio de Janeiro: Editora Carioca, 1950-1959.

Miriam Waidenfeld Chaves, doutora em Educação pela Pontifícia Universidade Católica do Rio de Janeiro (PUC-RJ), é professora adjunta II e pesquisadora na área de História da Educação da Universidade Federal do Rio de Janeiro (UFRJ).

miriamfeld@terra.com.br

Recebido em 7 de março de 2009.

Aprovado em 15 de abril de 2010. 